\title{
Potential gains through selecting for resistance in spotted gum to Quambalaria pitereka
}

\author{
G. S. Pegg • L. S. Shuey • A. J. Carnegie • \\ M. J. Wingfield $\cdot$ A. Drenth
}

Received: 19 August 2010 / Accepted: 19 December 2010 /Published online: 27 January 2011

(C) Australasian Plant Pathology Society Inc. 2011

\begin{abstract}
Quambalaria shoot blight, caused by the fungus Quambalaria pitereka, is a serious disease affecting the expanding eucalypt plantation estate in subtropical and tropical eastern Australia. Trees that are severely infected are often multi-stemmed and stunted and infection of young trees may give rise to poor form in mature trees. A spotted gum clonal trial provided the opportunity to investigate the impact of the disease on tree growth and factors influencing tree architecture (tree form), which affects wood quality. We measured the effect that $Q$. pitereka infection during plantation establishment (up to 6 months old) has on growth and tree architecture and productivity to age 3 years. Our results show that the pathogen has a significant impact on trees at plantation establishment, which results in a negative impact on wood quality, potentially reducing merchantable value at final harvest. Tree growth and form was significantly improved where germplasm with low susceptibility to $Q$. pitereka infection was used.
\end{abstract}

G. S. Pegg • L. S. Shuey

Horticulture and Forestry Science, Agri-Science Queensland,

Brisbane, Queensland 4068, Australia

G. S. Pegg $(\bowtie) \cdot$ A. Drenth

Tree Pathology Centre,

The University of Queensland/Agri-Science Queensland,

Brisbane, Queensland 4068, Australia

e-mail: geoff.pegg@deedi.qld.gov.au

\author{
A. J. Carnegie \\ Forest Science centre, Industry and Investment NSW, \\ Beecroft, New South Wales 2119, Australia \\ M. J. Wingfield \\ Forestry and Agricultural Biotechnology Institute, \\ University of Pretoria, \\ Pretoria, Gauteng 0002, South Africa
}

Keywords Corymbia C. variegata . Disease impact - Tree improvement

\section{Introduction}

A source of high value logs for sawn timber products is required to replace the declining supplies from native forests in subtropical eastern Australia and this has seen the rapid expansion of spotted gum plantations in Queensland and northern New South Wales. Spotted gum, including Corymbia citriodora subsp. citriodora, $C$. citriodora subsp. variegata (hereafter referred to as $C$. variegata), C. henryi and C. maculata, is a valuable timber resource and is suitable for various end uses (Kynaston et al. 2001; Boland et al. 1992). It is a hard and durable timber and is attractive as a product for joinery furniture and other high value products. Spotted gum can be used for sawn or round timber in engineering works, unseasoned timber in general framing and construction, joinery and fencing, fine and outdoor furniture and parquetry and turnery. Studies have indicated that plantation grown spotted gum has timber qualities comparable to those derived from native forests (Kynaston et al. 2001). However, Quambalaria shoot blight, caused by the fungus Quambalaria pitereka, is a serious disease that threatens the expansion of spotted gum plantations in Australia (Simpson 2000; Self et al. 2002; Carnegie 2007b; Pegg et al. 2008).

In order to better understand the impact of Quambalaria shoot blight on plantation development, Self et al. (2002) assessed a number of provenances and species in artificially inoculated field trials. The impact of infection on growth was found to be a reduction in height increment with increasing severity of $Q$. pitereka infection. Stone et 
al. (1998) also found that all species and provenances of spotted gum used in trial sites in New South Wales suffered repeated infections by $Q$. pitereka, resulting in a significant loss of height increment and stem form. An increase in apical branching on trees that had suffered from Quambalaria shoot blight was also noted. In surveys of young plantations in NSW, Carnegie (2007b) found that up to $35 \%$ of trees were severely damaged by Quambalaria shoot blight, but in most cases, older plantations ( $>5$ year old) had small numbers of trees with significant damage, suggesting that trees may recover from early infection. However, a small number of these older plantations had up to $25 \%$ of trees severely, and repeatedly, damaged. Trees that were severely infected are often stunted and multi-stemmed (Carnegie 2007a, b). Although several authors have reported stunted, bushy trees associated with QSB damage (Simpson 2000; Carnegie 2007a; Pegg et al. 2008),, the recovery and impact on stem architecture (stem straightness, branch size) has not been quantified.

Spotted gum breeding trials have been established in Queensland and New South Wales with variability in susceptibility to $Q$. pitereka identified at the species, provenance and progeny levels. Johnson et al. (2009), when assessing a spotted gum provenance and progeny trial in New South Wales, indicated that Quambalaria shoot blight had a detrimental effect on growth of young spotted gum. Quambalaria shoot blight negatively affected growth, for all individual trees, families, and provenances tested. Johnson et al. (2009) also found that families and provenances with high mean Quambalaria damage scores, tended to have low mean stem straightness scores and above average numbers of forks and ramicorns. Ramicorns are defined as very steep-angled branches, previously forming a competing leader, but over-taken by the dominant leader (Johnson et al. 2009). Lan et al. (2010) made similar observations when assessing clonal spotted gum trials indicating that tree growth traits were strongly negatively correlated with the level of $Q$. pitereka infection in young trees. Faster growing clonal trees had higher disease tolerance, which was similar to that reported by Johnson et al. (2009). However, Lan et al. (2010) did not take into account the effect of infection by $Q$. pitereka on stem architecture. Although Johnson et al. (2009) assessed trees for the presence of ramicorns, this was not specifically in relation to $Q$. pitereka infection.

Forests NSW have focused on development of clonal seed orchards using superior trees selected from provenance and progeny trials. During the course of the last ten years, trials of $C$. variegata have been established on multiple sites to enable selection of clones (Smith et al. 2007). Four sites were planted with a total of 69 clones selected from families within New South Wales spotted gum provenances. A subset of 33 clones was then selected for further assessment based on height, stem diameter, Quambalaria tolerance and Crown Damage Index (CDI, Stone et al. 2003). Nine of the best performing clones were selected from these trials for pilot scale production. Access to this material allowed us to assess these nine clones for growth, form and susceptibility to $Q$. pitereka at 6 months (establishment phase), two years and three years, and to evaluate the impact of the disease. The overall objective of our study was to determine the influence $Q$. pitereka infection during the early establishment phase has on the development of trees as the plantation ages. The specific research questions we sought to address were: (1) whether there are differences in levels of susceptibility to $Q$. pitereka within and among clones (2) whether there is a correlation between levels of foliage infection and severity of green stem and apical stem infection, (3) whether a relationship exists between the level of susceptibility at 6 months, and tree growth and form two and three years after plantation establishment, and further quantify the influence of infection on stem architecture over time.

Identifying resistance to $Q$. pitereka within spotted gum species is crucial for the development of plantation hardwoods in Australia. Quantifying the gains of identifying resistance to $Q$. pitereka is yet to be demonstrated and is paramount to steer tree breeding strategies towards development of more resistant lines. In addition, quantification is important to enable optimization of the selection process to improve resistance to $Q$. pitereka.

\section{Methods}

A trial including nine clones of $C$. variegata was established in 2006 at Grafton in northern New South Wales using a 25 tree randomised block design with four replicates per treatment. Incidence and severity of Quambalaria pitereka infection was assessed under conditions optimal for repeat infection and high inoculum levels. The trial was established in close proximity to native spotted gum forests during a period of above average rainfall. Quambalaria pitereka symptoms were identified on mature trees and seedlings in the understory of the surrounding native spotted gum trees. Prior to assessment, a transect study was conducted to determine whether infection by $Q$. pitereka was evenly spread throughout the trial. Plants for each clone were produced from micro-propagation of archived cultures developed by Forests NSW (Lan et al. 2010). These nine clones were derived from 33 clones selected for growth and resistance to $Q$. pitereka in four trials established in NSW in 2003 . 
Infection during establishment

To determine the difference in levels of susceptibility among clones, assessments for incidence and severity on new shoots and expanding foliage were conducted 6 months after planting. Incidence (I) was calculated as a percentage of new shoots and immature, expanding foliage showing visible signs of Quambalaria shoot blight, and severity (S) the percentage of total area of infected new shoots and immature, expanding foliage. In addition, the incidence of juvenile green stems infected with $Q$. pitereka was recorded and an apical infection rating applied to determine the influence of infection on maintenance of apical dominance. In the latter case a rating score of $1=$ no infection by $Q$. piterek $; 2=$ minor lesion development on the apical stem and shoots; $3=$ multiple lesions on apical stem; $4=$ entire apical stem covered in lesions; $5=$ apical stem killed, was applied.

Influence of susceptibility on tree form over time

To determine the effect of susceptibility to $Q$. pitereka on tree form, assessments were also conducted on the same trees as above at two and three years after plantation establishment. Tree form was rated where $1=$ apically dominant, no evidence of stem death due to $Q$. pitereka infection; $2=$ double leader due to infection; $3=$ multiple leaders resulting from infection, light levels of foliage infection present; $4=$ shrub like appearance due to infection of all stems, light to moderate levels of foliage infection; $5=$ shrub like appearance due to infection of all stems and with all shoots and stems heavily infected and $6=$ tree killed due to infection (Pegg et al. 2010). The influence of foliage, stem and apical infection at the time of establishment on tree form was also examined.

The influence of susceptibility on tree growth

To determine the importance of susceptibility to Q. pitereka on tree growth, clones were assessed for height and diameter at breast height $(1.3 \mathrm{~m})$ three years after planting. On trees with multiple stems, the tallest was measured. On trees forking below $1.3 \mathrm{~m}$ height, the stem with apical dominance was measured.

Impact on stem architecture

In order to assess the influence of disease on stem architecture (and the benefit of identifying germplasm with low susceptibility to $Q$. pitereka), stem straightness, branch thickness and the frequency of ramicorns was assessed three years after planting. Stem straightness was based on the number of "kinks" in the main stem from tree base to apex where a score of $1=$ no kinks; $2=$ a single kink; $3=2-3$ kinks and $4=$ more than 3 kinks in the main stem. Branch thickness was also scored using a 1-4 rating scale where $1=$ thin evenly distributed branches along main stem; $2=$ majority of branches thin with some level of clumping along the main stem; $3=$ clumping of branches of moderate thickness; $4=$ clumping of branches of substantial thickness. The number of ramicorns per tree was also assessed as an indicator of frequency of loss of apical dominance during tree growth.

Analysis

Normality of the data was assessed using an equality of variance $\mathrm{F}$ test. All proportion data, which were not normally distributed, were Arcsine square root transformed prior to analysis using ANOVA and compared using Fisher's PLD post hoc test (Statview ${ }^{\circledR}$ ). Back-converted data were used to present data graphically. Correlations to determine the interdependence of disease levels, growth and stem architecture were conducted. Bonferroni correction was applied for multiple comparisons.

\section{Results}

The transect evaluation showed that symptoms of $Q$. pitereka infection were present evenly throughout the trial site. No significant differences in infection were found between replicates of the same clone based on the initial 6 month assessment (Fig. 1). No other significant pests, diseases or nutritional disorders were observed within the trial during the period of assessment.

Infection during establishment

Susceptibility to $Q$. pitereka differed significantly between clones of spotted gum when assessing incidence $\left(\mathrm{F}_{8,27}=9.9\right.$; $P<0.0001)$ and severity $\left(\mathrm{F}_{8,27}=17.1 ; P<0.0001\right)$ of foliage infection and incidence of stem infection $\left(\mathrm{F}_{8,27}=9.8\right.$; $P<0.0001)$ six months after plantation establishment (Fig. 2). Significant differences in the level of apical infection caused by $Q$. pitereka were identified on the different spotted gum clones assessed $\left(\mathrm{F}_{8,27}=16.2\right.$; $P<0.0001$ ) (Fig. 3). Spotted gum clone 6 had a significantly lower level of apical infection than all other clones (clone 2, $P=0.002$; clone $1, P=0.0009$; clones $10,8,4,5$ and 9, $P<0.0001)$ except clone $3(P=0.2)$.

Susceptibility ranking

Based on the incidence and severity of foliage infection, incidence of stem infection and level of apical infection, 
Fig. 1 Replicated block layout of a clonal spotted gum trial in Grafton, northern New South Wales indicating mean $Q$. pitereka incidence levels on spotted gum clones. $\mathrm{Mac}=C$. maculata mixed provenance replicated part of the experimental design but not included in this study

\begin{tabular}{|c|c|c|c|}
\hline $\begin{array}{c}\text { Clone } 6 \\
\text { R3 }\end{array}$ & & & $\begin{array}{c}\text { Clone } 8 \\
\text { R1 }\end{array}$ \\
\hline $\begin{array}{c}\text { Clone } 1 \\
\text { R3 }\end{array}$ & & & $\begin{array}{c}\text { Clone } 5 \\
\text { R1 }\end{array}$ \\
\hline $\begin{array}{c}\text { Clone } 5 \\
\text { R3 }\end{array}$ & $\begin{array}{c}\text { Clone } 8 \\
\text { R2 }\end{array}$ & Mac R2 & $\begin{array}{c}\text { Clone } 3 \\
\text { R1 }\end{array}$ \\
\hline $\begin{array}{c}\text { Clone } 3 \\
\text { R3 }\end{array}$ & $\begin{array}{c}\text { Clone } 1 \\
\text { R2 }\end{array}$ & $\begin{array}{c}\text { Clone } 3 \\
\text { R2 }\end{array}$ & $\begin{array}{c}\text { Clone } 4 \\
\text { R1 }\end{array}$ \\
\hline $\begin{array}{c}\text { Clone } 4 \\
\text { R3 }\end{array}$ & $\begin{array}{c}\text { Clone } 10 \\
\text { R2 }\end{array}$ & $\begin{array}{c}\text { Clone } 5 \\
\text { R2 }\end{array}$ & $\begin{array}{c}\text { Clone } 10 \\
\text { R1 }\end{array}$ \\
\hline $\begin{array}{c}\text { Clone } 10 \\
\text { R3 }\end{array}$ & $\begin{array}{c}\text { Clone } 9 \\
\text { R2 }\end{array}$ & $\begin{array}{c}\text { Clone } 4 \\
\text { R2 }\end{array}$ & $\begin{array}{c}\text { Clone } 9 \\
\text { R1 }\end{array}$ \\
\hline Mac R3 & $\begin{array}{c}\text { Clone } 2 \\
\text { R2 }\end{array}$ & $\begin{array}{c}\text { Clone } 1 \\
\text { R1 }\end{array}$ & $\begin{array}{c}\text { Clone } 6 \\
\text { R1 }\end{array}$ \\
\hline $\begin{array}{c}\text { Clone } 9 \\
\text { R3 }\end{array}$ & $\begin{array}{c}\text { Clone } 6 \\
\text { R2 }\end{array}$ & $\begin{array}{c}\text { Clone } 2 \\
\text { R1 }\end{array}$ & Mac R1 \\
\hline $\begin{array}{c}\text { Clone } 8 \\
\text { R3 }\end{array}$ & $\begin{array}{c}\text { Clone } 2 \\
\text { R3 }\end{array}$ & & \\
\hline
\end{tabular}

\begin{tabular}{|c|c|}
\hline $\begin{array}{c}\text { Clone 10 } \\
\text { R4 }\end{array}$ & $\begin{array}{c}\text { Clone 3 } \\
\text { R4 }\end{array}$ \\
\hline Mac R4 & $\begin{array}{c}\text { Clone 2 } \\
\text { R4 }\end{array}$ \\
\hline $\begin{array}{c}\text { Clone 1 } \\
\text { R4 }\end{array}$ & $\begin{array}{c}\text { Clone 5 } \\
\text { R4 }\end{array}$ \\
\hline $\begin{array}{c}\text { Clone 6 } \\
\text { R4 }\end{array}$ & $\begin{array}{c}\text { Clone 9 } \\
\text { R4 }\end{array}$ \\
\hline $\begin{array}{c}\text { Clone 4 } \\
\text { R4 }\end{array}$ & $\begin{array}{c}\text { Clone 8 } \\
\text { R4 }\end{array}$ \\
\hline
\end{tabular}

$\mathrm{R}=$ Replicate

Incidence of $Q$. pitereka infection (\%)

\begin{tabular}{|l|l|}
\hline & $81-100$ \\
\hline & $61-80$ \\
\hline & $41-60$ \\
\hline $21-40$ \\
\hline $0-20$ \\
\hline
\end{tabular}

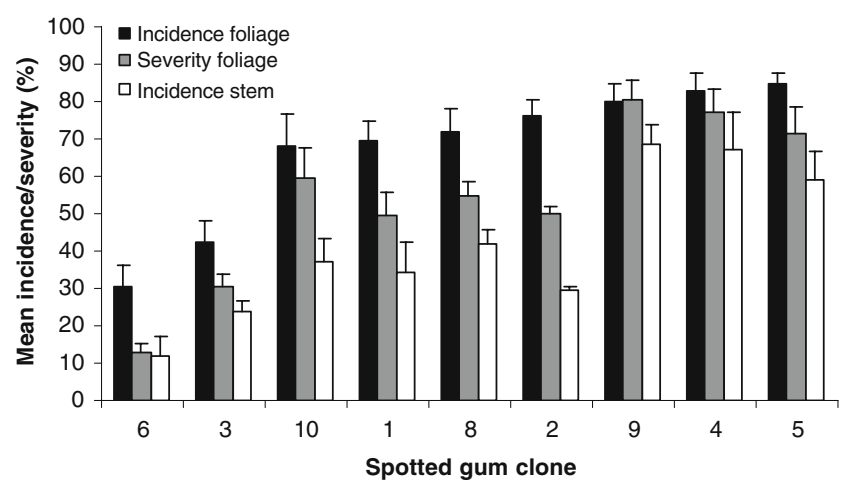

Fig. 2 Incidence and severity levels of $Q$. pitereka infection on spotted gum foliage and incidence of stem infection recorded six months after plantation establishment

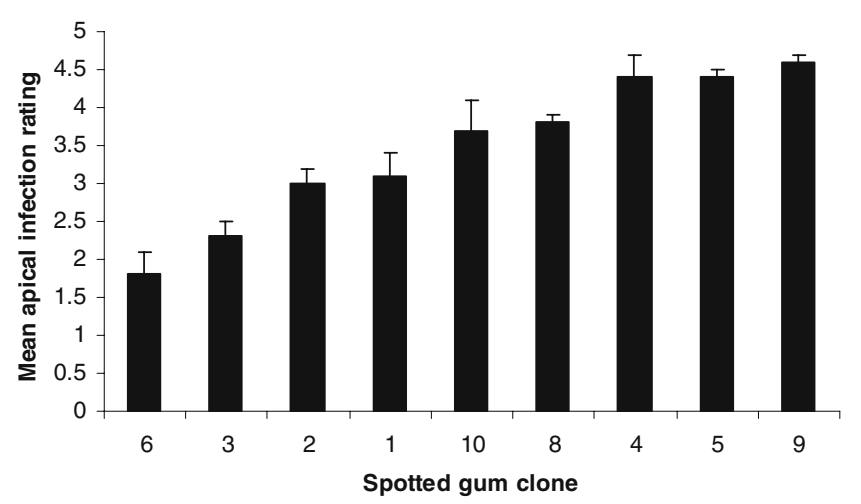

Fig. 3 Quambalaria pitereka infection on apical stems six months after plantation establishment on spotted gum clones 
clones were ranked as having low, moderate or high levels of disease susceptibility. Clone 6 was the least susceptible with the lowest incidence and severity of foliage and stem infection (Fig. 2). Clones 1, 3, 8 and 10 showed moderate levels of susceptibility to Q. pitereka and clones 4, 5 and 9 were highly susceptible (Table 1).

Influence of susceptibility on tree form over time

Significant differences were identified between clone form at two $\left(\mathrm{F}_{8,27}=82.7 ; P<0.0001\right)$ and three $\left(\mathrm{F}_{8,27}=30.2 ; P<\right.$ 0.0001) years after planting (Fig. 4). Symptoms of $Q$. pitereka infection were detected on trees at two years of age but not on three year old trees. The least susceptible clone (clone 6) was least affected by disease and remained apically dominant. Clones 4, 5 and 9, suffering high levels of disease during establishment, lacked apical dominance and had a shrub like appearance (Fig. 4). Clone 8 had poor apical form two years after planting and had the worst recorded stem form score three years after planting. Clone 10 was rated as a multi-branching tree with poor apical dominance two years after planting, but showed evidence of improved apical dominance three years after planting.

Influence of susceptibility on tree growth

Susceptibility to $Q$. pitereka influenced tree growth with height $\left(\mathrm{F}_{8,27}=36.9 ; P<0.0001\right)$ and stem diameter $\left(\mathrm{F}_{8,27}=\right.$ $8.3 ; P<0.0001)$ differences significant between clones having different levels of susceptibility. Tree height (Figs. 5 and 6) was significantly greater on the least susceptible clone in comparison to clones rated as moderately and highly susceptible $(P<0.0001)$. Of all the clones, clone 2 was the shortest, despite being only moderately susceptible during initial assessments. Stem form ratings two and three years after planting indicated that this clone was affected by $Q$. pitereka more seriously over time, in comparison to other clones.

Stem diameter on the least susceptible clone (clone 6; Fig. 7), was significantly greater than moderately and highly susceptible clones (Clones $4,3, P=0.002$; clone 1 , $P=0.001$; clone $8, P=0.0001$; clones 5, 9 and $2, P<0.0001)$ with the exception of clone $10(P=0.2)$. Clone 4 , a clone with poor apical form and one of the shortest clones, had the fourth largest stem diameter based on rankings.

Impact of infection on stem architecture

\section{Stem straightness}

The number of kinks in the main stems of clones was significantly higher in clones showing moderate or high levels of susceptibility to $Q$. pitereka at the time of establishment $\left(\mathrm{F}_{8,27}=11.9 ; P<0.0001\right)$. Clone 6 , the least susceptible clone, had significantly fewer stem kinks (Figs. 6 and 8 ) than moderately and highly susceptible clones $(P<0.0001)$. Clone 10 was the next best clone, but still had a mean score greater than two, indicating at least one kink per stem, significantly more than clone $6(P=$ 0.0002). The most susceptible clones $(9,4$ and 5) had the greatest number of kinks per stem with mean score above three (Fig. 8).

\section{Branch frequency and thickness}

Branch frequency and thickness increased with increasing susceptibility to $Q$. pitereka. There were significant differences between clones with low, moderate and high levels of susceptibility to $Q$. pitereka $\left(\mathrm{F}_{8,27}=4.4 ; P=0.002\right)$ (Fig. 9). Branch thickness was lowest on clone 6 as was the

Table 1 Susceptibility ranking of clones based on disease severity rating assessments conducted six months after planting

\begin{tabular}{llllll}
\hline $\begin{array}{l}\text { Spotted gum } \\
\text { clone number }\end{array}$ & $\begin{array}{l}\text { Ranking incidence } \\
\text { foliage infection }\end{array}$ & $\begin{array}{l}\text { Ranking severity } \\
\text { foliage infection }\end{array}$ & $\begin{array}{l}\text { Ranking incidence } \\
\text { stem infection }\end{array}$ & $\begin{array}{l}\text { Ranking apical } \\
\text { infection }\end{array}$ & $\begin{array}{l}\text { Quambalaria pitereka } \\
\text { susceptibility level }\end{array}$ \\
\hline 1 & 4 & 4 & 4 & 4 & Moderate \\
2 & 6 & 3 & 3 & 3 & Moderate \\
3 & 2 & 2 & 2 & 2 & Moderate \\
4 & 8 & 8 & 8 & 7 & High \\
5 & 9 & 7 & 7 & 1 & High \\
6 & 1 & 1 & 1 & 6 & Low \\
8 & 5 & 5 & 6 & 9 & Moderate \\
9 & 7 & 9 & 9 & 5 & High \\
10 & 3 & 6 & 5 & Moderate \\
\hline
\end{tabular}

$\mathrm{R}=$ Replicate

Incidence of $Q$. pitereka infection (\%) 


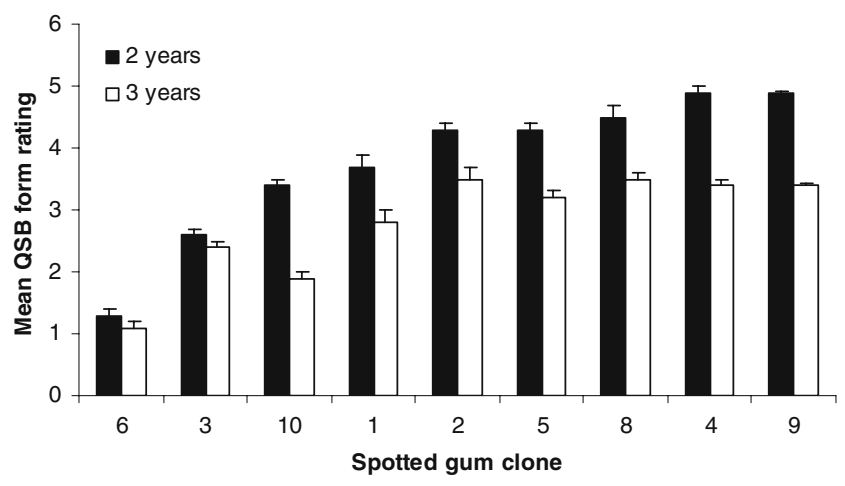

Fig. 4 The impact of $Q$. pitereka on tree form two and three years after plantation establishment

frequency of branches on the lower stem (Fig. 10). Highly susceptible clones had comparatively thick branches, often forming in clumps and at short intervals along the lower part of the stem (Fig. 10).

\section{Ramicorns}

The number of ramicorns per tree increased with increasing susceptibility to $Q$. pitereka. Significant differences in the number of ramicorns was identified when comparing clones having different levels of susceptibility to $Q$. pitereka $\left(\mathrm{F}_{8,27}=7.1 ; P<0.0001\right)$ (Figs. 10 and 11$)$. Clone 6 , with the lowest susceptibility to $Q$. pitereka, had significantly fewer ramicorns per stem than all other moderately and highly susceptible clones (clones $3, P=0.002$; clone 1, $P=0.0005$; clone 10, $P=0.0009$; clone $2, P=0.0003$; clones $9,8,4,5, P<0.0001)$.

\section{Relationships between infections during establishment and growth and form parameters}

There was a very strong correlation between incidence of foliage infection and severity (Spearman's Rank Correlation Coefficient $\{$ rho $\}=0.9 ; P<0.0001$ ) as well as incidence of stem infection $(\mathrm{rho}=0.6 ; P<0.001)$ and apical infection (rho=0.7; $P<0.0001$ ) (Bonferroni correction was used; $P=$ 0.005). Similarly, a strong correlation was identified between severity of foliage infection and stem incidence $($ rho $)=0.7 ; P<0.0001)$ and apical infection $($ rho $=0.8$; $P<0.0001)$.

There was a strong interdependence between disease incidence and severity of foliage infection and tree form two (rho $=0.8 ; P<0.0001)$ and three years $($ rho $=0.7,0.6$; $P<0.0001)$ after planting. Similar co-relationships were found with incidence of stem infection $(\mathrm{rho}=0.7,0.6$, $P<0.0001)$ and apical infection $(\mathrm{rho}=0.8,0.6 ; P<0.0001$, $P=0.0001)$.

A strong negative correlation was found between tree height and incidence $($ rho $=-0.7 ; P<0.0001)$ and severity (rho $=-0.6 ; P=0.0002)$ of foliage infection. The corelationship with tree height and incidence of stem infection (rho $=-0.5 ; P=0.002)$ and severity of apical infection (rho $=-0.5 ; P=0.001$ ) was not as strongly correlated. The co-relationship between disease levels at establishment and DBH was weak.

There were significant co-relations between disease levels at establishment (6 months) and stem straightness, branch frequency and thickness, and the number of ramicorns in older trees ( 3 years old). Stem straightness and the number of ramicorns were strongly correlated to the incidence $(\mathrm{rho}=0.7 ; P<0.0001)$ and severity (rho= $0.7 ; P<0.0001)$ of foliage infection. A strong positive correlation was identified between apical infection levels and stem straightness $(r h o=0.5 ; P=0.001)$, branch thickness $(\mathrm{rho}=0.6 ; P=0.0001)$ and the number or ramicorns $($ rho $=0.6 ; P<0.0001)$.

\section{Discussion}

The results of this study show significant differences among clones in their susceptibility to $Q$. pitereka for all parameters assessed. In the absence of any other significant pests, diseases or nutritional disorders, growth was significantly reduced in trees showing moderate to high levels of susceptibility to $Q$. pitereka. There was also good evidence to show that the disease results in serious damage to tree form and stem architecture, which will significantly impact on value and quality of plantation-grown timber. Increases in the number of stem kinks, branch frequency and angle was correlated with increasing levels of infection at establishment. These factors will impact negatively on production through reduced wood quality.

Our study clearly shows that infection soon after planting can have lasting effects on tree form and architecture. While our results suggest that tree form

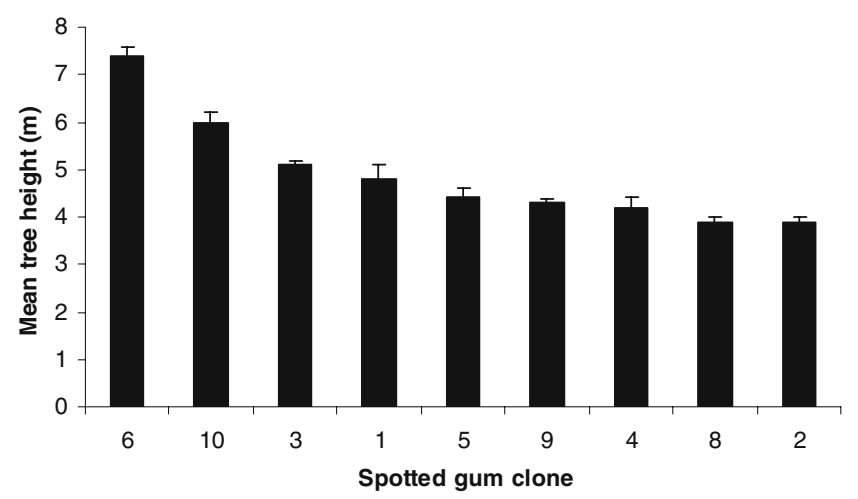

Fig. 5 Tree heights of spotted clones measured three years after plantation establishment to determine the influence of host susceptibility and infection by $Q$. pitereka on tree growth 

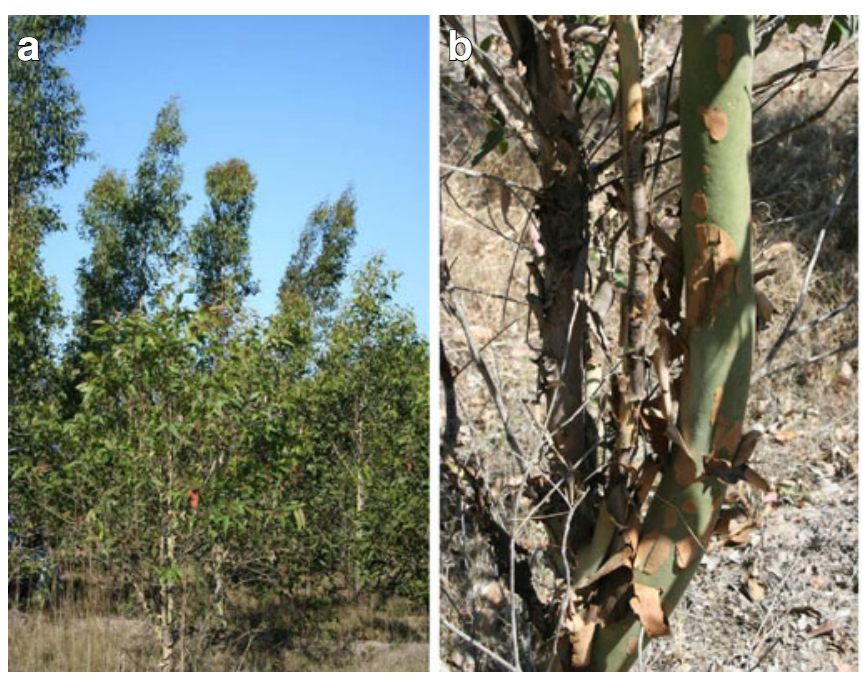

Fig. 6 Infection of establishing spotted gum seedlings by $Q$. pitereka results in a significant impact on tree growth and form. (a) Differences in levels of susceptibility to $Q$. pitereka resulted in significantly different growth rates with the least susceptible clone (background)

improves over time, moderately and highly susceptible clones continued to lack apical dominance. It has previously been suggested that susceptibility to $Q$. pitereka may decline as trees age and that this results in a subsequent improvement in form. Carnegie (2007b) reported that, in most cases, older plantations ( $>5$ year old) had fewer trees with significant damage than younger plantations. Carnegie (2007b) did not, however, assess tree form, only identified trees with severe and obvious QSB damage.

A comparison can also be drawn between $Q$. pitereka and the eucalypt rust fungus Puccinia psidii that causes serious damage to young trees, with damage diminishing as trees increase in height (Glen et al. 2007). Like Q. pitereka, infection of young, growing shoots and leaves by $P$. psidii can cause shoot death, defoliation and death of young trees. Infection by $P$. psidii has resulted in reduced growth and poor form in eucalypt plantation seedlings, and loss of almost entire plantings (Coutinho et al. 1998; Glen et al. 2007). However, unlike Quambalaria shoot blight, eucalypt trees escape infection by $P$. psidii as they grow, with trees greater than 3-4 m generally not showing any symptoms (Zauza et al. 2010). In contrast, Quambalaria pitereka has been identified causing foliage blight and stem cankers on mature spotted gum trees in native forests and amenity plantings (Simpson 2000; Pegg et al. 2008). It is, therefore, highly likely that trees showing high levels of susceptibility at establishment will continue to be infected and show evidence of poor apical dominance and large lateral branches.

Disease symptoms continued to appear on two year old trees but were absent at three years of age. In addition to changes in host susceptibility over time, climatic conditions
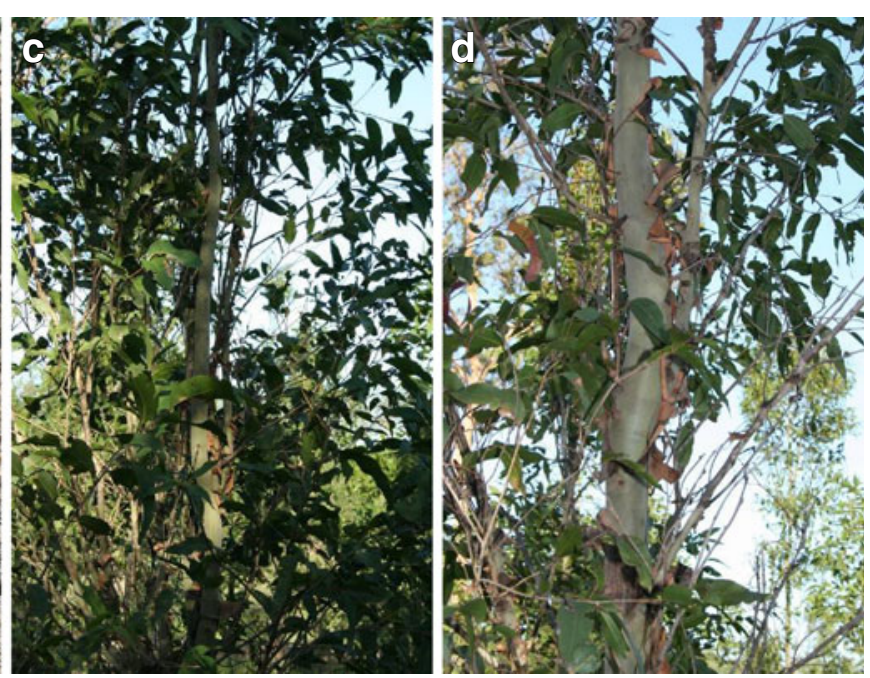

maintaining apical dominance in comparison to highly susceptible clones which have a shrub like growth habit (foreground). Kinks in the stems $(\mathbf{b}, \mathbf{c}, \mathbf{d})$ on some trees were initiated in the tree base and often bent in different directions

also influence disease severity and impact. The late onset of the wet season, rather than a change in host susceptibility, may be the reason disease was not observed in the third year of our trials. Rainfall levels during the normally wet months of November and December, the time of assessment, were low (Bureau of Meteorology 2010) and not conducive to disease development (Pegg et al. 2009). The presence of ramicorns in different positions up the stems of the more susceptible clones is perhaps a useful indicator of the number of $Q$. pitereka infection events. This is because ramicorns provide an indication of a loss of apical dominance and the likely death of the apical shoot due to infection by $Q$. pitereka (Johnson et al. 2009).

Infection by $Q$. pitereka on foliage during plantation establishment reduced tree growth significantly. Infection of immature foliage, new shoots and juvenile stems resulted

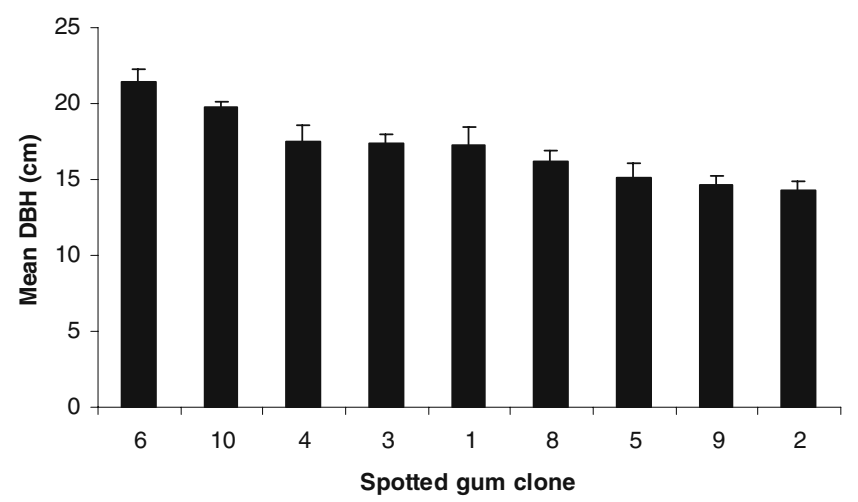

Fig. 7 Tree diameter measured three years after plantation establishment as an indicator of tree growth and the influence of host susceptibility to $Q$. pitereka 


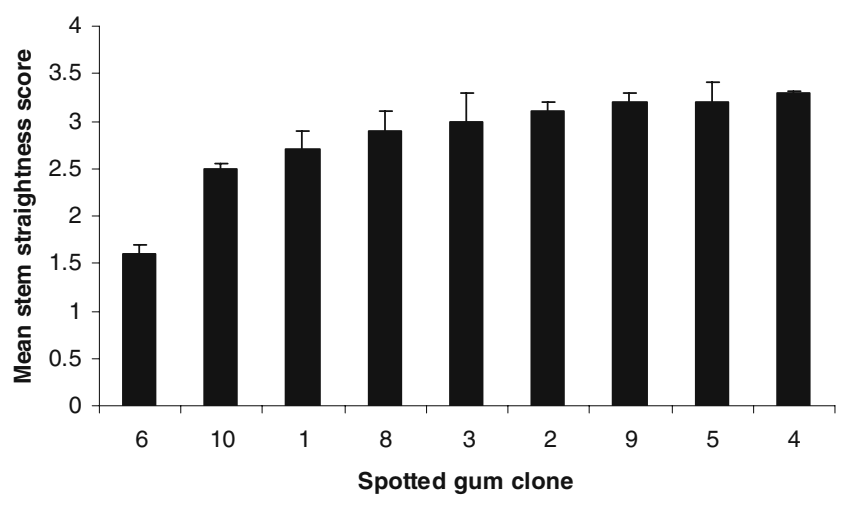

Fig. 8 The impact of Quambalaria pitereka on stem straightness and the influence of differences in disease susceptibility measured three years after plantation establishment

in a significant reduction of photosynthetic area and loss of foliage due to premature senescence over time. The effects of defoliation on trees is primarily due to a reduction in carbohydrate production and increased demand for carbohydrate reserves to re-foliate (Kozlowski 1969), resulting in a reduction in tree growth. In this regard, the crown is the source of wood-building carbohydrates and the quality and type of crown has a significant impact on the amount and quality of wood produced (Punches 2004). Economic returns from plantations are also sensitive to delays in harvest age caused by slower than projected growth (Candy and Gerrand 1997). New foliage has been shown to have the highest levels of photosynthetic activity (Ericsson 1978; Troeng and Linder 1982) and, as Q. pitereka damages these leaves as well as killing the new shoots, then the impact of this disease on growth is likely to be higher than an agent that just damages leaves. In this respect $Q$. pitereka not only slows the growth of trees, but it impacts negatively on wood quality through repeated damage to the foliage.

Stem diameter was also significantly reduced with increased levels of foliage infection by $Q$. pitereka as seedlings established. These results are similar to those of Milgate et al. (2005) who followed the effects of a disease outbreak on E. globulus caused by Teratosphaeria (Mycosphaerella) nubilosa and showed that damage had a significantly deleterious impact on tree growth. In that study, the top $10 \%$ of families showing elevated disease resistance had a greater mean DBH than the trial mean. Milgate et al. (2005) suggested that a large component of this gain was due to disease resistance. Likewise, selection of $Q$. pitereka resistant germplasm and subsequent development of seed orchards using this material offers the potential for rapid gains in productivity as the actual yield is brought closer to the yield potential already present in these clones.

Factors impacting on wood quality were significantly greater in trees showing moderate to high levels of $Q$. pitereka infection during plantation establishment. While tree growth measurements suggested some recovery from infection (eg. clone 10), the number of kinks in the stems, branch thickness and number of ramicorns was significantly greater than on trees with low susceptibility to infection (eg. clone 6). Wood of the greatest commercial value comes from the straight main stem of the tree (Bootle 2005) and this is where there is the greatest proportion of mature wood relative to juvenile wood is found (Punches 2004; Bootle 2005). While three years is not a long period to fully determine the potential for tree recovery from a growth perspective, the impact of $Q$. pitereka infection on the lower part or butt end of the tree is already obvious at that time. Stem straightness, branch thickness/frequency and the presence of ramicorns have the potential to significantly downgrade the quality of the timber. As most of the current plantings in Australia have been established for use as saw-logs, this will have a significant bearing on the profitability of spotted gum plantings if control measures for $Q$. pitereka are not implemented.

Kinks in the stems in the lower half of trees were in significantly greater number in clones classed as moderately or highly susceptible to $Q$. pitereka. While internal sawing studies are required to confirm wood quality issues, large numbers of kinks will be associated with greater levels of reaction wood with subsequent downgrading of timber quality. The presence of reaction wood, formed within trees to straighten the stem, results in reduced wood quality as the timber is weaker, prone to shrinkage and often has a different colour (Haygreen and Bowyer 1982; Punches 2004; Bootle 2005). All clones exhibiting moderate to high levels of susceptibility to $Q$. pitereka had greater than two kinks per stem, suggesting a potentially significant downgrade in timber quality and therefore plantation value.

Branch thickness and frequency as well as the number and size of ramicorns in the lower stem were significantly greater in moderately and highly susceptible clones. Size and number of large branches, as well as vitality, is known to influence wood quality and cost of production through the persistence of knots and increased susceptibility to

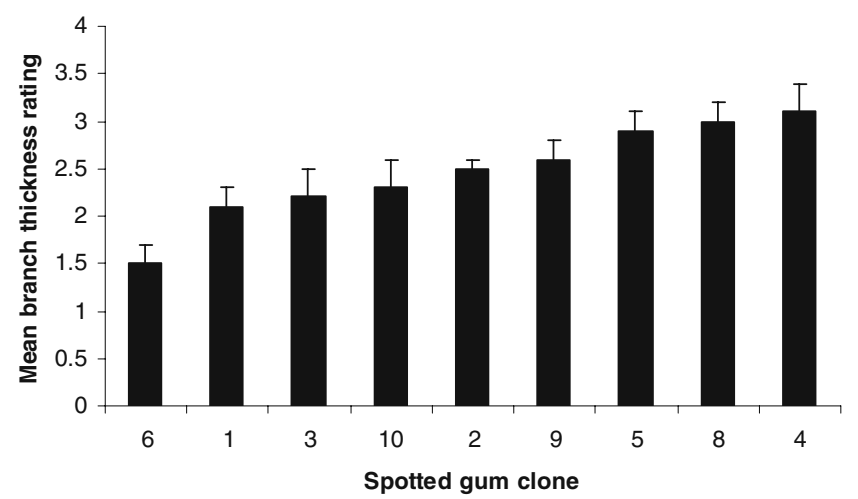

Fig. 9 The thickness and frequency of branches assessed on different spotted gum clones three years after establishment 

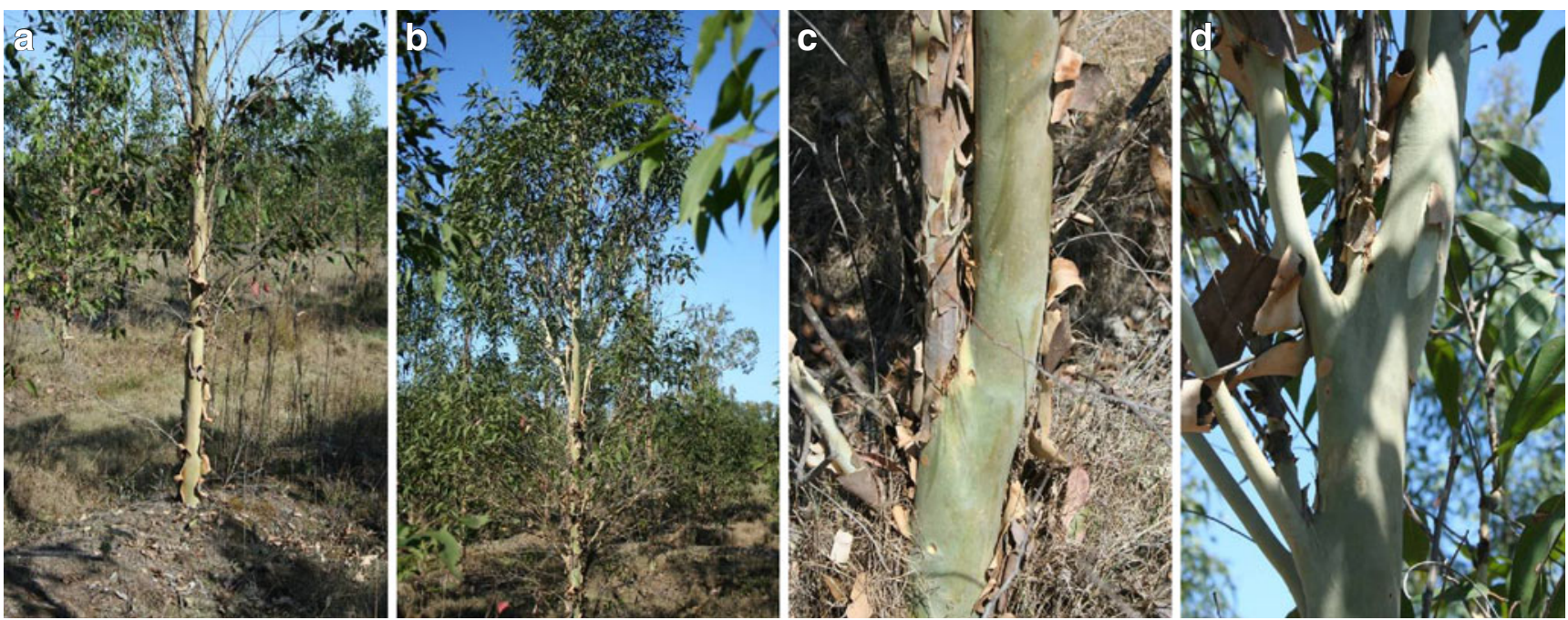

Fig. 10 Branch size and frequency increased significantly with increasing levels of $Q$. pitereka infection. The least susceptible clone 6 had thin, infrequent branches (a) in comparison to more susceptible clones which had frequent branches which were comparatively thicker. The incidence of ramicorns increased with increasing severity

decay (Nielsen and Gerrand 1999). Knots and knot-related defects are the major causes of timber degrade in solid wood eucalypt plantations (Yang and Waugh 1996; Washusen et al. 2000). Studies of E. nitens (Gerrand et al. 1997) and E. regnans (Glass et al. 1989) have shown infection by decay fungi through pruned branch stubs increases with increasing branch size. The significance of branch size and decay levels have not been studied for spotted gum species. Current plantation management programs also differ between states with Queensland pruning spotted gum and New South Wales opting not to do so. However, Nicholas (1992) suggests that branch diameter was important in both pruned and unpruned eucalypt stems with respect to decay.

Decay is not the only issue that influences stem quality affected by branches and branch knots. If pruning is required, then the cost of this action increases with increasing branch size and frequency, with wounds taking

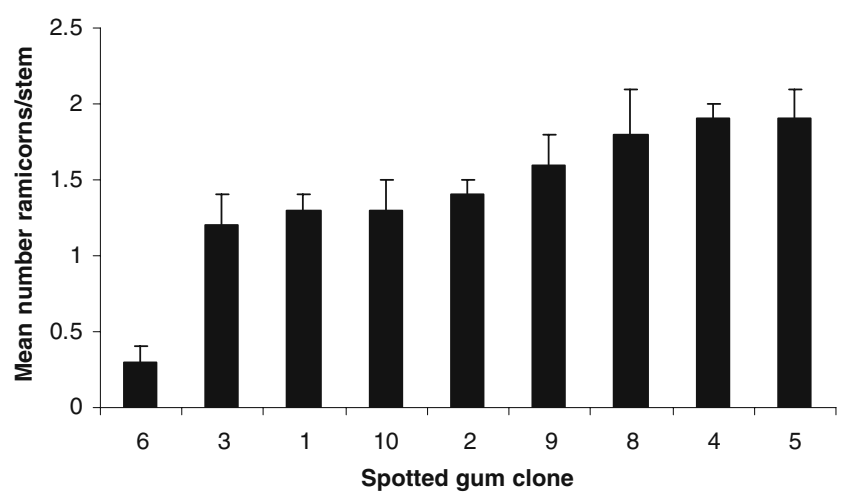

Fig. 11 The number of ramicorns on spotted gum clones was assessed three years after plantation establishment of infection by $Q$. pitereka. Ramicorns were present in lower (c) and upper (d) parts of the tree indicating different times when there was a lack of apical dominance and likely death of the apical shoot due to infection by $Q$. pitereka

longer to overgrow on larger branches (Smith et al. 2006). In addition to this, larger branch knots result in greater levels of degrade in the final product (Alcorn et al. 2008). The frequency of ramicorns was also reduced when susceptibility to $Q$. pitereka was low. Ramicorns typically form as a result of infection and death of the apical shoot caused by $Q$. pitereka. The frequency, size and angle of these ramicorns will have a significant impact on wood quality. More acutely angled branches, or ramicorns in this case, have the potential to increase the sectional area of knots and knot defects in comparison to branches forming along the stem at lesser angles (Henskens et al. 2001; Alcorn et al. 2007). Acutely angled branches have been shown to delay the branch shedding and stub ejection processes and they delay the production of clear-wood, which reduces wood quality (Alcorn et al. 2007). This would suggest that even if spotted gum trees recover from loss of apical dominance and reduced growth rate due to infection by $Q$. pitereka at establishment, the influence of infection on branch size will continually affect management and timber grading.

Increased susceptibility of spotted gum to $Q$. pitereka infection has the potential not only to impact on establishment of seedlings, but also to reduce the value of the timber at harvest. While trees do not necessarily die from infection, their growth and form continue be affected, particularly those that show high levels of susceptibility. Results of this study and previous research (Johnson et al. 2009; Lan et al. 2010) show that growth traits and stem architecture are strongly correlated with disease susceptibility. Thus, improvements through the selection of $Q$. pitereka resistance would enhance spotted gum productivity for both saw-log and pulping operations. Continuing to measure trees in the trial used in 
the present study will provide opportunities to study aspects of tree recovery and should be coupled with sawing studies to quantify the impact of this disease on wood quality.

Acknowledgments We thank Queensland Department Primary Industries Innovation and Biosecurity Program Investment, Forest Plantations Queensland, Integrated Tree Cropping, Forest Enterprises Australia and Forests NSW for providing the necessary funding for this research. We also thank Michael Henson and Helen Smith and Forests NSW for access to trial sites. We thank Dr Helen Nahrung for assistance with statistical analysis of field data.

\section{References}

Alcorn PJ, Pyttel P, Bauhus J, Smith RGB, Thomas D, James R, Nicotra A (2007) Effects of initial planting density on branch development in 4-year-old plantation grown Eucalyptus pilularis and Eucalyptus cloeziana trees. For Ecol Manage 252:41-51

Alcorn PJ, Bauhus J, Smith RGB, Thomas D, James R, Nicotra A (2008) Growth response following green crown pruning in plantation-grown Eucalyptus pilularis and Eucalyptus cloeziana. Can J For Res 38:770-781

Boland DJ, Brooker MIH, Chippendale GM, Hall N, Hyland BPM, Johnston RD, Kleinig DA, Turner JD (1992) Forest Trees of Australia. CSIRO Publishing, Victoria

Bootle KR (2005) Wood in Australia; types, properties and uses, 2nd edn. McGraw Hill Companies, Sydney

Bureau of Meteorology (2010) Grafton, New South Wales Daily Weather Observation. www.bom.gov.au

Candy SG, Gerrand AM (1997) Comparison of financial returns from sawlog regimes for Eucalyptus nitens plantations in Tasmania. Tasforests 9:35-50

Carnegie AJ (2007a) Forest health condition in New South Wales, Australia, 1996-2005. I. Fungi recorded from eucalypt plantations during forest health surveys. Australas Plant Pathol 36:213-224

Carnegie AJ (2007b) Forest health condition in New South Wales, Australia, 1996-2005. II. Fungal damage recorded from eucalypt plantations during forest health surveys and their management. Australas Plant Pathol 36:225-239

Coutinho TA, Wingfield MJ, Alfenas AC, Crous PW (1998) Eucalyptus rust: A disease with the potential for serious international implications. Plant Dis 82:819-825

Ericsson A (1978) Seasonal changes in translocation of ${ }^{14} \mathrm{C}$ from different age-classes of needles on 20-year-old Scots pine trees (Pinus silvestris). Physiol Plant 43:351-358

Gerrand AM, Neilsen WA, Medhurst JL (1997) Thinning and pruning eucalypt plantations for sawlog production in Tasmania. Tasforests 9:15-34

Glass BP, McKenzie H, Griffith JA (1989) Decay distribution in relation to pruning and growth stress in plantation-grown Eucalyptus regnans in New Zealand. NZ J For Sci 19:210-222

Glen M, Alfenas AC, Zauza EAV, Wingfield MJ, Mohammed C (2007) Puccinia psidii: a threat to Australian environment and economy - a review. Australas Plant Pathol 36:1-16

Haygreen JG, Bowyer JL (1982) Forest products and wood science; an introduction. The Iowa State University Press, Iowa

Henskens FL, Battaglia M, Cherry ML, Beadle CL (2001) Physiological basis of spacing effects on tree growth and form in Eucalyptus globulus. Trees 15:365-377

Johnson IG, Carnegie AJ, Henson M (2009) Growth, form and Quambalaria shoot blight tolerance of spotted gum provenances and families in north-eastern New South Wales, Australia. Silvae Genet 58:180-191

Kozlowski TT (1969) Tree physiology and forest pests. J Forest 67:118-123

Kynaston WT, Eccles DB, and Hopewell GP (2001) Spotted gum. Timber Species 14. Revised series. Queensland Forestry Research Institute, AFFS, DPI, Brisbane

Lan J, Raymond CA, Smith HJ, Thomas DS, Henson M, Carnegie AJ, Nichols JD (2010) Variation in growth and Quambalaria tolerance of clones of Corymbia citriodora subsp. variegata planted on four contrasting sites in north eastern NSW. Aust For, Submitted 2010

Milgate AW, Potts BM, Joyce K, Mohammed C, Vaillancourt RE (2005) Genetic variation in Eucalyptus globulus for susceptibility to Mycosphaerella nubilosa and its association with tree growth. Australas Plant Pathol 34:11-18

Nicholas IE (1992) Pruning eucalypts. NZ Tree Grower 13:18-20

Nielsen WA, Gerrand AM (1999) Growth and branching habit of Eucalyptus nitens at different spacing and the effect on final crop selection. For Ecol Manage 123:217-229

Pegg GS, O’Dwyer C, Carnegie AJ, Wingfield MJ, Drenth A (2008) Quambalaria species associated with plantation and native eucalypts in Australia. Plant Pathol 57:702-714

Pegg GS, Webb RI, Carnegie AJ, Wingfield MJ, Drenth A (2009) Infection and disease development of Quambalaria spp. on Corymbia and Eucalyptus species. Plant Pathol 58:642-654

Pegg GS, Carnegie AJ, Wingfield MJ, Drenth A (2010) Variable resistance to Quambalaria pitereka in spotted gum reveal opportunities for disease screening. Australas Plant Pathol 40:76-86

Punches J (2004) Tree growth, forest management and their implications for wood quality. A Pacific northwest extension publication, Oregon State University

Self NM, Aitken EAB, Dale MD (2002) Susceptibility of provenances of spotted gums to Ramularia shoot blight. NZ Plant Prot 55:68-72

Simpson JA (2000) Quambalaria, a new genus of eucalypt pathogens. Australasian Mycologist 19:57-62

Smith RGB, Dingle J, Kearney D, Montagu K (2006) Branch occlusion after pruning in four contrasting sub-tropical eucalypt species. J Trop For Sci 18:117-123

Smith HJ, Henson M, Boyton S (2007) Forests NSW' spotted gum (Corymbia spp.) tree improvement and deployment strategy. Proceeding of the inaugural Australasian Forest Genetics Conference, Breeding for Wood Quality, 10-14 April 2007, Hobart, Tasmania, Australia. www.proceedings.com.au/afgc

Stone C, Simpson JA, Eldridge RH (1998) Insect and fungal damage to young eucalypt trial plantings in northern New South Wales. Aust For 61:7-20

Stone C, Matsuki M, Carnegie A (2003) Pest and Disease Assessment in Young Eucalypt Plantations: Field Manual for Using the Crown Damage Index (Ed. M. Parsons). National Forestry Inventory, Bureau of Rural Sciences, Canberra

Troeng E, Linder S (1982) Gas-exchange in a 20-year-old stand of Scots' pine I. Net photosynthesis of current and 1-year-old shoots within and between seasons. Physiol Plant 54:7-14

Washusen R, Waugh G, Hudson I, Vinden P (2000) Appearance product potential of plantation hardwoods from medium rainfall areas of the southern Murray-Darling Basin. Green product recovery. Aust For 63:66-71

Yang JL, Waugh G (1996) Potential of plantation-grown eucalypts for structural sawn products. II. Eucalyptus nitens (Dean \& Maiden), Maiden and E. regnans F. Muell. Aust For 59:99-107

Zauza EAV, Couto MMF, Lana VM, Maffia LA, Alfenas AC (2010) Vertical spread of Puccinia psidii urediniospores and development of eucalyptus rust at different heights. Australas Plant Pathol 39:141-145 